University of Nebraska - Lincoln

DigitalCommons@University of Nebraska - Lincoln

Faculty Publications, Department of Psychology

Psychology, Department of

January 2000

\title{
Conditioned place preference: what does it add to our preclinical understanding of drug reward?
}

M. T. Bardo

University of Kentucky, mbardo@pop.uky.edu

Rick A. Bevins

University of Nebraska-Lincoln, rbevins1@unl.edu

Follow this and additional works at: https://digitalcommons.unl.edu/psychfacpub

Part of the Psychiatry and Psychology Commons

Bardo, M. T. and Bevins, Rick A., "Conditioned place preference: what does it add to our preclinical understanding of drug reward?" (2000). Faculty Publications, Department of Psychology. 48.

https://digitalcommons.unl.edu/psychfacpub/48

This Article is brought to you for free and open access by the Psychology, Department of at DigitalCommons@University of Nebraska - Lincoln. It has been accepted for inclusion in Faculty Publications, Department of Psychology by an authorized administrator of DigitalCommons@University of Nebraska - Lincoln. 


\section{M.T. Bardo • R.A. Bevins}

\section{Conditioned place preference: what does it add to our preclinical understanding of drug reward?}

Submitted January 2000; accepted August 2000; published online November 2000; published December 2000.

\begin{abstract}
Rationale: Among the various experimental protocols that have been used to measure drug reward in laboratory animals, conditioned place preference (CPP) has been one of the most popular. However, a number of controversial issues have surrounded the use of this experimental protocol. Objective: The present review provides a theoretical overview of some critical issues relevant to CPP. The advantages and limitations of CPP are also covered. Results: Based on modern and traditional theoretical formulations of Pavlovian conditioning, CPP appears to reflect a preference for a context due to the contiguous association between the context and a drug stimulus. Within this theoretical framework, it seems clear that CPP measures a learning process that is fundamentally distinct from drug self-administration. The main advantages of CPP are that it: (1) tests animals in a drugfree state; (2) is sensitive to both reward and aversion; (3) allows for simultaneous determination of CPP and locomotor activity; (4) is adaptable to a variety of species; (5) typically yields dose-effect curves that are monophasic rather than biphasic; and (6) has utility in probing the neural circuits involved in drug reward. The main limitations of CPP are that it: (1) is subject to interpretation based on the notion of novelty seeking; (2) is cumbersome for providing the graded dose-effect curves needed for answering some pharmacological questions; (3) is difficult to interpret when animals prefer one context prior to drug conditioning; and (4) lacks face validity as an experimental protocol of drug reward in humans. Conclusion: Despite some limitations, CPP provides unique information about the rewarding effect of contextual cues associated with a drug stimulus.
\end{abstract}

M.T. Bardo: Department of Psychology, University of Kentucky, Lexington, KY 40506, USA; e-mail: mbardo@pop.uky.edu

R.A. Bevins Department of Psychology, University of NebraskaLincoln, Lincoln, NE 68588, USA; email: rbevins1@unl.edu
Keywords: Conditioned place preference (CPP), Pavlovian conditioning, Drug reward, Drug self-administration, Drug abuse

\section{Introduction}

The purpose of this review is to provide an evaluation of conditioned place preference (CPP) as an experimental protocol for measuring drug reward in laboratory animals. We have chosen to refer to CPP as a protocol for measuring drug "reward", rather than "reinforcement", in order to distinguish it from the drug self-administration protocol. Reinforcement is typically defined as any experimental contingency (operant or Pavlovian) that increases the probability of a class of behaviors, whereas reward typically refers to the appetitive nature of a given stimulus (Mackintosh 1974). Since it is not clear what class of behaviors are reinforced during CPP conditioning trials, the term reward seems more appropriate to describe drug-induced CPP. As an experimental protocol for measuring drug reward, we will provide an overview of the critical theoretical issues relevant to this protocol, especially as it relates to the self-administration protocol. In addition, we will provide a critical summary of the advantages and limitations of the protocol. That is, when should CPP be used and when should it not be used? Each of these issues is addressed using a question and answer format. We have not attempted to provide a comprehensive or bibliographic compilation of all available CPP studies in answering the posed questions, as a number of comprehensive reviews of the CPP literature are already available (Carr et al. 1989; Hoffman 1989; Schechter and Calcagnetti 1993; Bardo et al. 1995; Tzschentke 1998). We have attempted to minimize redundancy with points made in these previous publications.

\section{What is CPP?}

CPP has become a popular alternative to drug self-administration for assessing the rewarding effects of a variety of 
drugs (Carr et al. 1989; Schechter and Calcagnetti 1993; Tzschentke 1998). Perhaps the earliest antecedent to the currently used CPP procedure was a study conducted by Spragg (1940). In that study, chimpanzees were given daily injections of morphine by an experimenter. After becoming morphine-dependent, the chimpanzees were then trained to choose between a white box that hid a syringe filled with their daily dose of morphine and a black box that hid a banana. When deprived of morphine, the chimpanzees chose to open the white box, but when pretreated with their daily dose of morphine, the chimpanzees chose to open the black box. Based on this seminal work with chimpanzees, Beach (1957) found that morphine-dependent rats could also be trained to choose the white arm of a Y-maze when it was paired with morphine using a discrete trial choice procedure. Importantly, Beach (1957) also found that the morphine-paired white arm was preferred to an unpaired black arm in non-dependent rats, indicating that the induction of physical dependence is not a prerequisite for obtaining CPP. Following this demonstration of CPP using a discrete trial choice procedure, Rossi and Reid (1976) published a report of morphine CPP in which the duration of time spent in a morphine-paired context relative to a saline-paired context was used as the index of preference. To date, the general procedure described by Rossi and Reid (1976) has been adopted for essentially all subsequent CPP studies, with some modifications.

Although methodological details differ among laboratories, a typical CPP experiment includes differentially pairing two distinct sets of environmental (contextual) cues with the stimulus of interest (e.g., drug, food, copulatory opportunity). The contextual cues tend to differ along several stimulus dimensions. For example, the contexts may vary in flooring, size or shape, wall color or pattern, and olfactory cues. Conditioning involves an animal receiving repeated access to the appetitive stimulus (termed unconditioned stimulus or US) in one context (termed conditioned stimulus or CS). Intermixed with these context-US pairings is similar exposure to the other context without the US.

Following conditioning is a choice test in which animals receive unrestricted exposure to both contexts in the absence of the US. An increase in time spent in the paired context relative to a control value is taken as evidence that the US was rewarding. Presumably, the learned association between the context CS and the US results in animals spending more time in that context. Research has shown that a wide array of stimuli can condition an increase in preference. For example, access to "natural" appetitive stimuli like food (Spyraki et al. 1982a), water (Ågmo et al. 1993), sweet fluids (Ågmo and Marroquin 1997), conspecific interaction (Calcagnetti and Schechter 1992), wheel running (Antoniadis et al. 2000), copulation (Meisel et al. 1996), and novel stimuli (Bevins and Bardo 1999) can condition preferences in rodents. These preferences are subject to changes in motivational state, as food-deprived rats will prefer a context previously paired with food, whereas water-deprived rats will prefer a context previously paired with water (Perks and Clifton 1997). Of specific interest to the present review are the conditioned place preferences displayed when a drug of abuse serves as the US (for a recent review, see Tzschentke 1998). Under the appropriate conditions, drugs such as cocaine (Nomikos and Spyraki 1988), amphetamine (Spyraki et al. 1982b), methamphetamine (Trazon et al. 1992), morphine (Bardo et al. 1984), nicotine (Shoaib et al. 1994), ethanol (Reid et al. 1985), caffeine (Bedingfield et al. 1998), and $\triangle 9$ THC (Lepore et al. 1995) have rewarding effects as indexed by CPP.

\section{Is CPP isomorphic with self-administration?}

Since the early 1980s, there has been some disagreement about whether drug CPP and self-administration represent two alternative methods for measuring a common reward process. An early report by Katz and Gormezano (1979) declared that CPP was a "rapid and inexpensive technique for measuring drug reinforcement". Although this report presented only a limited amount of data, it was influential because it appeared in a pharmacology journal with a widespread readership. The few CPP studies that predated Katz and Gormezano (1979) were published in primarily psychology journals (e.g., Beach 1957; Rossi and Reid 1976) and those psychological reports emphasized CPP more as a learning phenomenon rather than a pharmacological tool. The important inference derived from the Katz and Gormezano (1979) report was that CPP and self-administration are isomorphic measures of a single drug process, namely reinforcement or reward. A logical extension of this inference was that CPP could be substituted for self-administration to measure drug reward. This extension is appealing because CPP requires no surgery, is relatively inexpensive, and requires relatively little training.

Partial support for the claim that CPP is isomorphic with self-administration may come when one compares the ability of each experimental protocol to detect reward across various drug classes. On balance, there appears to be reasonable concordance between drugs that produce CPP and drugs that are self-administered (see Table 1). This concordant relationship only exists with rats, as insufficient CPP data are available utilizing other species. Nonetheless, within this species, various stimulants, opiates and other drugs are known to support both CPP and self-administration. In contrast, neither CPP nor self-administration is produced by a host of other drug classes, including antagonists for dopamine, opioid, and cholinergic receptors, as well as antidepressants that work on either noradrenergic or serotonergic systems. Despite this parallel, however, there are some notable exceptions to the general concordance between CPP and self-administration across drug classes. Although limited data are available, CPP may be unique in its ability to detect the rewarding effect of lysergic acid diethylamide (LSD), buspi- 
Table 1 Examples of references showing concordance in the ability of drugs to produce $C P P$ and engender self-administration in rats

"The "4" symbol indicates a positive effect, the " 0 " symbol indicates no effect and the "-" symbol indicates an aversion

Table 2 Examples of references showing discordance in the ability of drugs to produce $C P P$ and engender self-administration in rats

"The "4" symbol indicates a positive effect and the " 0 " symbol indicates no effect

\begin{tabular}{|c|c|c|c|}
\hline Drug & CPpa & $\begin{array}{l}\text { Self- } \\
\text { administration" }\end{array}$ & Example references \\
\hline \multicolumn{4}{|l|}{ Stimulants } \\
\hline Ampletamine & + & + & Yokel and Wise 1976: Spyraki et al. 1982b \\
\hline Methamphetanine & + & + & Pickens et al 1967; Trazon et al. 1992 \\
\hline Cocaine & + & + & Nomikos and Spyraki 1988; Caine and Koob 1994 \\
\hline Nicotine & + & + & Conigall and Coen 1989: Shoaib et al. 1994 \\
\hline Caffeine & + & + & Atkinson and Enslen 1976; Bedingfield et al 1998 \\
\hline Methylphenidate & + & + & Martin-Iversen et al. 1985; Weeks and Collins 1987 \\
\hline Apomorphine & + & + & Baxter et al. 1974 ; Parker 1992 \\
\hline SKF 82958 & + & + & Self et al. 1996; Abrahams et al. 1998 \\
\hline Bromocriptine & + & + & Hoffiman et al. 1988; Wise et al. 1990 \\
\hline 7-OH-DPAT & + & + & Mallet and Beninger 1994; Caine et al. 1999 \\
\hline Bupropion & + & + & Ortmann 1985; Tella et al. 1997 \\
\hline \multicolumn{4}{|l|}{ Opiates } \\
\hline Morphine & + & + & Bardo et al. 1984; Glick et al. 1992 \\
\hline Heroin & + & + & Ettenberg et al. 1982; Hand et al. 1989 \\
\hline Fentanyl & + & + & Shearman et al. 1977; Mucha and Herz 1985 \\
\hline Methadone & + & + & Collins and Weeks 1965; Steinpreis et al. 1996 \\
\hline \multicolumn{4}{|l|}{ Other drugs } \\
\hline Ethanol & + & + & Reid et al 1985; Le et al. 2000 \\
\hline Diazepam & + & + & File 1986; Naruse and Asami 1990 \\
\hline Midazolam & + & + & Szostak et al $1987 ;$ Pain et al. 1997 \\
\hline$\Delta^{9}$-THC & + & + & Takahashi and Singer 1979; Lepore et al 1995 \\
\hline Clonidine & + & + & Shearman et al. 1977 ; Tierney et al. 1988 \\
\hline Scopolamine & 0 & 0 & Glick and Cox 1975 ; Lynch 1991 \\
\hline Haloperidol & 0 & 0 & Weeks and Collins 1987; Di Scala and Sandler 1989 \\
\hline Fenfluramine & - & 0 & Baxter et al. 1973; Davies and Parker 1993 \\
\hline Imipramine & - & 0 & Weeks and Collins 1987; Papp 1989 \\
\hline \multirow[t]{2}{*}{ Naloxone } & - & 0 & Weeks and Collins 1987; \\
\hline & & & Shippenberg and Bals-Kubik 1995 \\
\hline
\end{tabular}

\begin{tabular}{llll}
\hline Drug & CPPa & $\begin{array}{l}\text { Self- } \\
\text { administration* }\end{array}$ & Example references \\
\hline Pentobarbital & 0 & + & Collins et al. 1984; Lew and Parker 1998 \\
Phencyclidine & 0 & + & Marquis et al. 1989; Aquas et al. 1990 \\
LSD & + & 0 & Meehan and Schechter 1998 \\
Buspirone & + & 0 & Balster 1990; Neisewander et al. 1990 \\
Pentylenetetrazole & + & 0 & Gauvin et al. 1991 \\
\hline
\end{tabular}

rone, and pentylenetetrazole, whereas self-administration may be unique in its ability to detect the rewarding effect of pentobarbital and phencylclidine (Table 2). This discordance indicates that CPP and self-administration are not redundant measures of a common process. Some caution should be exercised in interpreting this discordance, however, as it is impossible to demonstrate that a drug will not produce CPP or be self-administered under any condition, at any dose.

In addition to the discordance between CPP and self-administration noted across some drug types, several recent studies have demonstrated a clear dissociation between CPP and self-administration. In one study from our laboratory (Bardo et al. 1999), we measured both the magnitude of amphetamine CPP and rate of amphetamine self-administration in a random sample of rats. Regardless of whether self-administration was measured on a fixed ratio (FR) or progressive ratio (PR) schedule of reinforcement, we found that individual differences in the magnitude of amphetamine CPP and the rate of amphetamine self-administration were not correlated. In another study, Deroche et al. (1999) allowed rats to self-administer cocaine for either six or 29 sessions and then examined these two groups for cocaine CPP, as well as for reinstatement of self-administration using a cocaine cue. Although the 29-session group self-administered more cocaine than the six-session group and showed greater sensitivity to cocaine's ability to reinstate operant responding, no group differences in the dose response curve for cocaine CPP were obtained. These results provide cogent evidence that CPP and self-administration are measuring fundamentally different processes.

There are also several concrete examples in the literature which indicate that the neuropharmacological mechanisms that underlie CPP and self-administration are dissociable. Perhaps the most notable illustration of this point comes from studies examining the effects of $\mathrm{D}_{2}$ dopamine antagonists on cocaine CPP and self-administration in rats. 
In general, studies have shown that systemic administration of cocaine induces a CPP that is not altered by pretreatment injections of various $\mathrm{D}_{2}$ antagonists administered either systemically (Spyraki et al. 1982c; Mackey and van der Kooy 1985; Morency and Beninger 1986; Cervo and Samanin 1995) or directly into the nucleus accumbens (Baker et al. 1996). This outcome contrasts with self-administration studies demonstrating that the reinforcing effect of cocaine using either FR or PR schedules is attenuated by $\mathrm{D}_{2}$ antagonists administered either systemically (Ettenberg et al. 1982; Roberts and Vickers 1984; Dalton et al. 1986; Roberts et al. 1989; Corrigall and Coen 1991; Caine and Koob 1994) or into the nucleus accumbens (Phillips et al. 1994). Although $\mathrm{D}_{2}$ antagonists administered prior to a self-administration session can produce non-specific effects on responding independent of reinforcing effects (e.g., Winger 1994), the increase in cocaine self-administration that occurs on an FR schedule following low doses of $\mathrm{D}_{2}$ antagonists is generally thought to reflect a decrease in the reinforcing effect of the self-administered cocaine. Thus, $\mathrm{D}_{2}$ dopamine receptors appear to be involved in the primary reinforcing effect of cocaine, but not in the rewarding effect of contextual stimuli paired with cocaine.

One important feature of CPP is that the drug is administered passively by the experimenter. This feature is distinct from the self-administration protocol in which the history of the drug experience is under the control of the animal. Recent evidence indicates that the ability of drugs to activate the mesolimbic dopamine system is dependent, at least in part, on whether the drug is administered passively or is under operant control by the animal. In general, the increase in dopaminergic activity observed with selfadministration of stimulant drugs is attenuated in yoked control animals that receive the drug passively (Di Ciano et al. 1996; Hemby et al. 1997; Stefanski et al. 1999). In contrast, compared to self-administration animals, yoked control animals show a more pronounced dopaminergic response in the nucleus accumbens following exposure to a stimulus previously paired with the amphetamine infusion (Di Ciano et al. 1998). Given these neurochemical differences in active and passive administration groups, it seems that the yoked control group in a drug self-administration experiment, rather than the self-administration group, is the more appropriate comparison to CPP.

In conclusion, there seems to be no reasonable argument remaining to support the claim that CPP and self-administration are isomorphic measures of drug reward. Rather than continuing any debate about whether CPP and self-administration are measuring a similar process, it seems that more effort should be expended on determining how CPP adds to our understanding of drug abuse liability beyond that which is obtained with self-administration alone.

\section{What is learned in CPP?}

In most CPP research, investigators assume that the context CS becomes associated with the drug US through a Pavlovian conditioning process. Although the bulk of research supports this assumption, what is required for the acquisition of the conditioned association between the context and the US? For over 100 years, there has been much empirical and theoretical effort spent on determining what factors are necessary for acquisition and later expression of conditioned associations between CSs and USs. In this section of the review, we will provide a summary of some of the current thinking and debate as it relates to CPP.

Early theorists argued that temporal contiguity was necessary and sufficient for learning (Pavlov 1927; Hull 1943). That is, the CS must occur close in time with the US. In most if not all CPP experiments, there is good temporal contiguity between the context CS and the drug US; the drug is often administered either immediately before or upon placement in the paired context. Presumed early failures in contiguity theory, however, lead to the competing theoretical position that information or a predictive and non-redundant relation between the CS and US was required for the acquisition of a conditioned association (Egger and Miller 1963; Rescorla 1967). In CPP experiments, there tends to be a perfect predictive relation between the context CS and drug administration; the drug US and context CS always co-occur.

Although different variants of information theory are in use, in recent years the theoretical pendulum has been swinging back to contiguity theory. This change is driven, in part, by an accumulation of failures of information theory and the ability of contiguity-based models to account for these failures (e.g., Benedict and Ayres 1972; Kremer 1974; Papini and Bitterman 1990; Savastano and Miller 1998). For example, information theory suggests that the best control procedure is one in which the probability of the US during the CS is equal to the probability of the US in the absence of the CS (Rescorla 1967). The CS presumably remains neutral because it does not predict the presence or the absence of the US in this "random control". However, excitatory conditioning has been repeatedly reported with this control procedure (e.g., Benedict and Ayres 1972; Kremer 1974). This conditioning results from accidental contiguous pairings of the CS and US early in training, even though there is no overall predictive relation between the CS and US. Indeed, to avoid such situations the most popular and widely accepted control group in CPP is the explicitly unpaired control group. In this control, contiguous occurrences of the CS and drug US are avoided by never allowing the drug to be administered close in time to the context CS. Well-controlled experiments use this unpaired control in combination with control groups that receive only exposure to the CS and/or to the drug US to assess the potential influence of inhibitory conditioning (see later). 
An important question that arises from the current discussion is what event is temporally contiguous with the CS in a CPP experiment. That is, what becomes associated with the context CS? Perhaps the most widely accepted answer is the stimulus conditions produced by the drug (cf. Solomon and Corbit 1974; Eikelboom and Stewart 1982). As argued earlier, the CPP protocol provides a measure of the rewarding effect of the drug US similar to that postulated by opponent process theories (Solomon and Corbit 1974). The rewarding effect has a temporal profile that presumably increases and then decreases across the time since administration. Consistent with this, Ettenberg et al. (1999) found that cocaine given either immediately or $5 \mathrm{~min}$ prior to placement into a context produced $\mathrm{CPP}$, whereas cocaine given $15 \mathrm{~min}$ prior to placement into a context produced a conditioned place aversion. This latter finding indicates that the temporal effect of cocaine is biphasic, with an initial period of positive effect, followed by a period of negative effect. Thus, the onset, offset and subsequent opponent process of drug-elicited effects are, in part, a function of the pharmacokinetics and pharmacodynamics of drug under study. As a further layer of empirically and theoretically interesting complexity, the pharmacokinetics and pharmacodynamics of a drug can change with repeated exposures.

Some behavioral protocols allow one to readily measure the temporal profile of the drug effect of interest. Drug discrimination is a good example where the temporal profile of the discriminative stimulus (cueing) effects of various abused drugs has been investigated (e.g., Jones et al. 1976; Pratt et al. 1983). In contrast, little is known about the temporal profile of the rewarding effects of many abused drugs. The CPP protocol seems well suited to investigate the temporal profile of reward and the necessary contiguous relation between this profile and the context CS for acquisition of a conditioned association. The limited literature attempting to elucidate the temporal profile of drug reward in the CPP situation has employed two main techniques: behavioral and pharmacological manipulations. A report by Bardo and Neisewander (1986) exemplifies the use of both techniques to elucidate some of the temporal qualities of the rewarding effect of acute morphine. In that study, rats received a single IV morphine infusion in one distinct context; a second distinct context was equally experienced but was not paired with drug before the preference test. One behavioral manipulation involved varying the temporal arrangement between the CS and US. This was accomplished by infusing morphine at different time intervals $(0,15$ or $25 \mathrm{~min})$ following the onset of a 30-min placement into the paired context. CPP was observed when morphine was infused immediately upon placement in the paired context. However, infusion of morphine either 15 or $25 \mathrm{~min}$ after exposure to the CS abolished this place conditioning effect. This technique provides some control of drug onset relative to the CS and illustrates the importance of close temporal proximity between context onset and reward onset in establishing morphine CPP.
The study by Bardo and Neisewander (1986) also utilized a pharmacological manipulation to examine the importance of the temporal arrangement between the context CS and drug US in producing morphine CPP. This was accomplished by infusing the opioid receptor antagonist naloxone to reverse the rewarding effect of morphine at prescribed times. Using the single-trial CPP procedure described earlier, morphine was infused immediately upon placement in the paired context and naloxone was administered either 15 or $30 \mathrm{~min}$ afterward. Naloxone treatment $30 \mathrm{~min}$ after morphine did not block CPP. In contrast, naloxone treatment 15 min after morphine completely blocked CPP. This technique provides control over the offset of the drug US and suggests that more than $15 \mathrm{~min}$ of the drug effect is required to produce CPP. It would also be possible to assess the temporal profile of drug reward by holding the administration time constant, while manipulating total duration in the paired context. Clearly, much work is needed to elucidate the nature of the rewarding effect and how its temporal profile changes with such factors as drug type, drug dose, treatment regimen (continuous versus intermittent), rearing environment and stress exposure (see Sherman et al. 1980). Relevant to this discussion is the ability of the CPP protocol to measure the postulated aversive effects of drug withdrawal (e.g., Mucha 1987; Suzuki et al. 1996). For example, Suzuki et al. (1996) found that rats avoided environmental cues in which nicotine withdrawal had occurred (i.e., a conditioned place aversion). Delineating the temporal characteristics of drug withdrawal and the underlying neural process has important implications for understanding drug abuse.

As mentioned previously, CPP is indexed by an increase in time spent in the drug-paired context during a preference test. Presumably, this measure reflects an increase in approach responses to the context and/or a change in the type or duration of behaviors once the paired context is encountered. Unlike drug self-administration where a predetermined class of responses (e.g., lever press) is followed by an experimenter programmed outcome (i.e., drug infusion), there is no explicit response requirement in the CPP protocol. Drug is passively administered while the animal is in the paired context. This procedural feature begs the question of how behavior change emerges from simply the close temporal pairing of the context CS and the stimulus conditions (reward in this case) induced by the drug. Current thinking would argue that rats have evolutionarily pre-disposed response tendencies (species-specific responses) to stimuli that have aversive or rewarding qualities (Bolles 1970; Ikemoto and Panksepp 1999). In CPP, the context takes on a secondary rewarding effect by virtue of its contiguous pairing with drug. Stimuli associated with rewarding effects, like the paired context in CPP, elicit approach behaviors. Of course, an important task for researchers will be to break the circularity of this argument by identifying the underlying neural processes mediating the acquisition of conditioned reward 
(or aversion) and to delineate the response systems modulated by this conditioned reward (Panksepp 1998; Ikemoto and Panksepp 1999). Further, it will be of interest to see the similarity and differences in these processes and those that mediate cue-elicited relapse in self-administration protocols (Pilla et al. 1999; Neisewander et al. 2000).

In most CPP experiments, the CS is a complex multi-modal stimulus (context) including distinct olfactory, visual, tactile, auditory, and spatial elements. Does each stimulus element enter into an association with the drug US, or does the variety of elements combine to form a single configural stimulus that then enters into an association with the US? Although there is evidence in the CPP literature that a single element (e.g., different tactile stimuli from flooring) can control a place preference (Vezina and Stewart 1987), the question of how the context CS is neurally coded has not been systematically addressed in CPP experiments. In contrast, a large portion of recent experimental and theoretical effort in the Pavlovian conditioning field has focused on distinguishing between elemental and configural models of CS processing and learning. Elemental theories suggest that each element that comprises the paired context enters into its own association with the US (e.g., Estes 1950; Rescorla and Wagner 1972; Bevins et al. 1997). The magnitude of the conditioned response is often assumed to be the sum of all the conditioned elements present and processed at the time of testing.

In contrast, configural theories propose that stimulus elements that comprise the context combine to form a single representation of the environment that would then enter into the association with the US. Configural theories often differ, for example, on how the elements within the representation combine, interact, and later induce conditioned responding depending on the stimuli present during testing (Sutherland and Rudy 1989; Pearce 1994; Hall 1996; Gluck and Meyers 1997; Rudy and O’Reilly 1999). For example, Pearce (1994) suggests that if stimulus elements A and B were present at the time of the US, a configural representation $\mathrm{AB}$ would be formed and enter into the association with the US. Later, presentation of the compound $\mathrm{AB}$ elicits strong conditioned responding because of the direct association with the US. If only one element was presented (e.g., A), then conditioned responding will be weaker in that $\mathrm{A}$ is only a portion of the configural $\mathrm{AB}$ cue that was associated with the US. In a recent thought provoking review, Fanselow (1999) argued that the behavioral and neural evidence supports the presence of both configural and elemental brain systems. If so, then an important task for researchers in the drug conditioning field will be to distinguish between the conditions that encourage elemental versus configural processing of conditioned stimuli, and to further delineate the neuroanatomical and neurobiological processes mediating each. This is an important issue for studies with CPP that typically use multimodal cues because the form of a drug-induced CR may vary as a function of the type of CS used to establish conditioning (Bevins and Bardo 1998).
While our discussion has focused on the context CS paired with the drug US (CXT+), CPP experiments are typically a successive discrimination task in which animals also receive equal exposure to a second distinct context not paired with the drug US (CXT-). Does learning occur to CXT- or does it remain neutral? It is likely that the organism becomes familiar with CXT-. Environmental familiarity is a form of learning in that changes in behavior occur as a result of experience with the context and those changes require neural storage of the stimulus elements that compose the context (Kimble 1961). Familiarity can alter place preferences. Rodents, in general, spend more time in a novel than a familiar context (Hughes 1968; Parker 1992; Bardo et al. 1993). Because animals receive equal exposure to both CXT+ and CXT-, environmental familiarity appears to be equated in CPP experiments. However, if the drug of interest interferes with familiarization, then place preferences may reflect the tendency of rats to spend more time in a novel environment $(\mathrm{CXT}+)$ rather than a conditioned association between the context and the rewarding effect of the drug (see later for more detailed discussion of this notion).

Some conditioning theories propose that stimuli that occur in the absence of an experimenter programmed US may be neurally represented as CS-no US associations (e.g., Pavlov 1927; Bouton 1993). A context-no US association may interfere with subsequent conditioning to that context. Thus, non-rewarded pre-exposure to contexts or pre-conditioning preference tests may interfere with subsequent acquisition and/or expression of a context-drug US association (Lubow et al 1976; Bouton 1993). In contrast, it is not clear whether a no-US association to one discrete context (CXT-) can interact with a drug US association in another context so as to alter choice behavior during a preference test. This is an important issue for those interested in drug reward mechanisms. The extent to which CPP is observed (expression) may depend differentially on how well the procedural details allow for acquisition of a context-drug association in CXT+ and a context-no drug association in CXT-.

Related to the previous discussion is the possibility that CXT - may be a conditioned inhibitor (e.g., Wagner 1981; Stewart 1992). Typically, for a stimulus to become a conditioned inhibitor, that stimulus must be presented in the presence of excitatory stimuli (i.e., stimuli that have acquired an association with the drug US), yet not be followed by the US (Rescorla 1969a). Clearly, CXT- is not followed by the US; it is less clear whether excitatory stimuli are present at the time of CXT- exposure. A strong case could be made that many of the procedural details that are similar from day to day in a CPP experiment may enter into an association with the drug US, thus providing the prerequisite excitatory cues required to produce a conditioned inhibitor. For example, handling and transport procedures, injection ritual, time of day, location of apparatus, and experimenter tend to be consistent. If these procedural details acquire an excitatory association with the drug US, then they may allow CXT- 
to become a conditioned inhibitor when later presented on non-rewarded trials. To our knowledge, no one has assessed whether CXT - in a CPP situation becomes a conditioned inhibitor (see Rescorla 1969b; Wasserman and Miller 1997 for testing protocols). This possibility has important theoretical and empirical implications. Conditioned inhibitors have been shown in other Pavlovian conditioning preparations to elicit avoidance responses (e.g., Wasserman et al. 1974). If CXT - is an inhibitor, research will need to determine whether CXT- elicits avoidance responses that contribute to the increase in time spent in the drug-paired context. That is, the measure of drug reward (increased time in $\mathrm{CXT}+$ ) might include approach to $\mathrm{CXT}+$, as well as avoidance of $\mathrm{CXT}-$.

In this section, we have not provided an exhaustive review of all theoretical issues relevant to CPP. For example, a recent and interesting theoretical view termed the "temporal coding hypothesis" argues that acquisition of a conditioned association is dependent on contiguity between the CS and US (Barnet et al. 1991; Savastano and Miller 1998). Automatically acquired as part of this association is when the US occurs in relation to the CS (i.e., temporal coding). Simply stated for the CPP protocol, did the rewarding effect occur before or after the context CS? Also, uncontrolled situational cues including the interoceptive state of the organism at the time of conditioning may also be an important part of what is learned during a CPP experiment. There are clear biological changes in an organism over time. As time passes, these stimuli also change, thus altering expression of conditioning (Bouton et al. 1999; for a differing view see Riccio et al. 1984). The fact that the US of interest in CPP is a drug, these cues may be especially important.

\section{What are the advantages of CPP?}

In a comprehensive review, Carr et al. (1989) indicated that the major advantages of CPP are that it: (1) is sensitive to low drug doses; (2) can be obtained using only a single drug pairing; (3) measures both reward and aversion; (4) is tested when the animal is in a drug-free state; (5) does not require a surgical procedure; and (6) controls for drug dosing. Among these advantages, the ability of CPP to measure drug reward using a single context-drug US pairing is perhaps the most unique advantage. With drug self-administration, repeated self-infusions of drug are required in order to establish reliable behavior and this repeated exposure protocol likely affects receptor transduction mechanisms related to tolerance and/or sensitization. In contrast, single-trial CPP has been demonstrated with morphine (Mucha et al. 1982; Bardo and Neisewander 1986), cocaine (Bardo et al. 1986) and amphetamine (Bardo et al. 1999). This procedural advantage allows for determining drug reward without any induction of tolerance or sensitization. Such information may be especially useful in studying the antecedent conditions related to initiation of drug use, since clinical evidence suggests that vulnerability to drug abuse may be predicted by the degree of positive reward derived from the initial drug experience (Haertzen et al. 1983).

In addition to the list of advantages offered by Carr et al. (1989), there at least four additional advantages of CPP that deserve mention. One advantage is that CPP is well suited for assessing locomotor activity concomitantly with drug reward. This advantage is important because an influential theory proposed over a decade ago is that there is a common brain circuitry underlying both drug reward and locomotor stimulation (Wise and Bozarth 1987). Drug-induced locomotor sensitization has also been widely studied in its own right and several mechanistic explanations of this phenomenon have been formulated (Kalivas et al. 1993; White and Kalivas 1998). With CPP, locomotor activity during drug conditioning trials can be readily monitored by either inserting photobeams into the context or by using a video tracking system. Acute and chronic changes in activity can then be analyzed as a separate dependent variable or as a correlative variable with the CPP measure. Interestingly, similar to the locomotor sensitization that develops to repeated injections of stimulants and opiates, CPP is enhanced by repeated drug injections of amphetamine, cocaine or morphine (Lett 1989). Despite this parallel, however, work in this area has shown that locomotor sensitization and development of CPP are dissociable effects (Shimosato and Ohkuma 2000), and thus reflect, at least in part, separate neural mechanisms.

Another advantage of CPP is that it is adaptable to a variety of laboratory animals beyond rats. For example, cocaine CPP has been demonstrated in chickens (Hughes et al. 1995). Because chickens have a highly evolved visual system sensitive to color and fine detail, Hughes et al. (1995) used visual stimuli as the CS to establish the CPP. This contrasts with the multimodal contextual cues (visual, tactile, olfactory) typically used with rats, a species that has a relatively poor visual capacity. Visually-based CPP in an avian species may offer some unique advantage in modeling conditioned drug effects that are obtained when visual drug-associated stimuli are presented to humans in a controlled laboratory setting (Childress et al. 1986; Liu et al. 1998). Such information may be important in discerning whether the mechanisms of conditioning differ depending on whether the contextual CS elements are distal (visual) or proximal (tactile, olfactory) to the individual.

Along with avians, CPP appears to be readily adaptable to mice. This versatility is important because the mouse is now the primary species used for genetic analyses of drug effects. One illustration of this point comes from recent work showing that knockout mice lacking either dopamine or serotonin transporter genes show robust cocaine and methylphenidate CPP (Sora et al. 1998), thus calling into question the widely held assumption that these monoamine transporters are critically involved in stimulant reward. CPP may also be useful in genetic analyses using the method of quantitative trait loci (QTL). The QTL method requires screening a number of recombinant inbred mouse strains in order to identify candi- 
date genetic loci for the trait of interest. CPP allows for such rapid screening. Indeed, Cunningham and colleagues have developed what appears to be a sensitive and optimally controlled CPP methodology for use in different mouse strains (Cunningham 1995; Cunningham et al. 1999).

Another advantage of CPP is that it typically yields a monophasic dose-effect curve. This pattern contrasts with self-administration experiments, which typically yield inverted U-shaped dose-effect curves (Yokel 1987; Stafford et al. 1998). Monophasic dose-effect curves are advantageous because they simplify statistical analysis and allow for a more definitive statement about the direction of change (either increase or decrease) in drug reward. Despite this advantage, it has been argued that CPP is not particularly sensitive to changes in drug dose (Wise 1989). That is, dose-effect CPP experiments often, but not always, yield a monophasic curve that appears to be all-or-none rather than graded. Importantly, a previous meta-analytic review of the CPP literature revealed that graded monophasic dose-effect curves are evident with morphine, heroin and amphetamine, but may be lacking for cocaine (Bardo et al. 1995). In addition, a somewhat overlooked study by Barr et al. (1985) demonstrated that the gradation in the CPP dose-effect curve can be sharpened by training rats with one of several different drug doses in one context and a single reference dose (rather than saline) in a different context. More work is needed to discern the methodological conditions under which the gradation in the CPP dose-effect curve is maximized across different drugs.

Finally, another advantage of CPP is that it has considerable utility in probing the neural circuits involved in drug reward. For example, microinjection of amphetamine into the nucleus accumbens produces CPP, whereas microinjection of amphetamine into the area postrema produces a conditioned taste aversion (Carr and White 1983, 1986). Other studies have shown that microinjection of $\mu$ opioids into the ventral tegmental area (VTA) produces CPP, whereas microinjection of $\kappa$ opioids into the VTA, nucleus accumbens, medial prefrontal cortex or lateral hypothalamus produces conditioned place aversion (Shippenberg and Elmer 1998). These place preference studies illustrate clearly that the neural circuits involved in drug reward are distinct from those involved in drug aversion.

\section{What are the limitations of CPP?}

One major concern regarding $\mathrm{CPP}$ is the potential confounding influence of novelty-seeking behavior on the test day. It is well established that rats prefer a novel context over a familiar context (Hughes 1968; Parker 1992; Bardo et al. 1993). This finding leads to the possibility that pairing the drug with one context retards or blocks completely familiarization to that context, thus rendering it more novel relative to the saline context on the drug-free test day. While virtually all CPP experiments to date are subject to this potential interpretation, it should be noted that the concept of reward seems to account for more of the data across CPP experiments than the concept of novelty seeking. Nonetheless, one way to directly handle the issue of novelty in any given experiment is to test animals in an apparatus that has three distinct contexts, one that is novel, one that is drug-paired, and one that is saline-paired. When tested in this situation, rats show a preference for the drug-paired context relative to the novel context (Mucha and Iversen 1984; Parker 1992), thus negating any novelty interpretation.

Importantly, the novelty interpretation of CPP is fundamentally distinct from the notion of state-dependent learning. An interpretation based on state dependency would posit that the stimulus effect of the drug itself plays a critical role in determining the relative novelty of each context. That is, since familiarization occurs to one context under drug influence, then this context $(\mathrm{CTX}+)$ would be relatively more novel (i.e., preferred) when the animal is tested in a drugfree state. While this notion seems plausible, a state-dependent interpretation would also posit that when animals are tested under the influence of the drug, they would prefer the saline-paired context (CXT-) because it would be relatively more novel. However, since animals prefer the drug-paired context regardless of whether they are tested with or without drug (Mucha and Iversen 1984), the notion that CPP reflects purely a state-dependent effect can be discounted. In addition, in the event that a given drug fails to produce CPP, one can readily assess the issue of state-dependency by administering the drug on the test day following conditioning.

In addition to the potential novelty confound, one of the most serious limitations of CPP is the difficulty in generating the type of dose-effect information normally expected in behavioral pharmacology. Although graded dose-effect curves may be generated under some methodological conditions, each point on the dose-effect curve requires an independent group of animals. This between-subject approach poses a practical limitation on the number of drug doses (including vehicle) that can be reasonably tested. Compounding this problem is the fact that the dose-effect results are not manifested until the final test day following conditioning, thus preventing adjustments in the doses tested as the experiment progresses. This contrasts with drug self-administration experiments in which within-subject dose-effect results are typically obtained across repeated sessions and dose adjustments can be made on a session-to-session basis in order to characterize completely the graded portions of the curve. Due to this limitation, CPP tends to be cumbersome for answering a number of critical pharmacological questions requiring full dose-effect curves, including questions related to whether a given treatment alters drug potency or efficacy, or whether a given antagonist effect is competitive or non-competitive.

Another limitation of CPP stems from the tendency of animals to prefer one of the two distinct contexts of the apparatus before conditioning occurs. A strong preference for one context creates a dilemma in which the experiment- 
er must choose between two problematic avenues: (1) pairing the drug with the preferred context, which may mitigate against showing CPP due to a ceiling effect; or (2) pairing the drug with the non-preferred context, which may produce CPP by reducing the aversion to that context rather than producing a true preference. Although reducing an aversion to a context may be a mechanism by which drugs have a rewarding effect, the best approach for conducting CPP experiments is to construct an apparatus that minimizes any strong bias in preference for either context. This can be a difficult challenge, especially since a bias may not be apparent with an initial test, but may emerge across repeated tests. Inherent differences in preference also pose a considerable obstacle for genetic analyses of CPP using inbred mouse strains, as strains may differ in the magnitude of inherent preference for one context, thus confounding the interpretation of shifts in preference following drug conditioning. Importantly, Cunningham et al. (1999) have developed an exemplar nonbiased procedure utilizing tactile cues to assess CPP across different mouse strains.

Finally, a lingering criticism of CPP is that it has not been validated as a protocol for measuring drug reward in either humans or non-human primates. One published report has shown that rhesus monkeys prefer a context associated previously with cocaine (Foltin and Evans 1997). In that report, however, the contextual preference differed from more traditional CPP studies because the cocaine was self-administered, rather than experimenter-administered, and the preference was only demonstrated when monkeys were tested under drug influence. More important, an experimental demonstration of CPP in humans is lacking altogether. It is notable that clinical investigators and behavioral pharmacologists have not pursued CPP in humans, especially since humans display a wide range of conditioned drug effects (Robbins and Ehrman 1992) and these effects are thought to play a prominent role in long-lasting compulsion and cue-elicited craving (O'Brien et al. 1998). Perhaps most relevant to CPP, humans will choose a pill previously associated with a drug experience over a pill previously associated with a placebo experience (de Wit 1991). However, until it is demonstrated that humans prefer an environmental context previously associated with a drug US over an unpaired context, the validity of CPP for understanding drug reward in humans will remain speculative.

\section{Concluding comment}

Drug abuse is a multi-faceted problem that requires an understanding of basic processes underlying drug reward from different levels of analysis. At the behavior analytic level, the ultimate goal is to reduce or abolish completely drugtaking behavior. From this perspective, drug self-administration offers a critical psychopharmacological tool. However, environmental cues associated with the drug experience also play a critical role in acquiring and maintaining drug- taking behavior because approach to a drug-associated context typically sets the occasion for drug-taking behavior to be engendered. Since context-drug associative learning is likely fundamentally distinct from the acquisition of a drugreinforced operant response, it is faulty to assume that the results obtained from CPP must mirror the results obtained from self-administration experiments. To the contrary, it is our view that CPP is a unique measure of drug reward that is sub-served by a neuropharmacological circuitry distinct, at least in part, from that which subserves self-administration. In this regard, it is important to note that the most recent formulations of the dopamine hypothesis of drug reward have emphasized that the nucleus accumbens shell may be more critically involved in strengthening context-drug associations than in mediating the direct rewarding effect of drugs of abuse (Di Chiara 1999; Spanagel and Weiss 1999). An understanding of the mechanisms involved in CPP may provide critical information for developing behavioral and pharmacological interventions to reduce contextual control of drug abuse.

Acknowledgements The authors were supported by USPHS grants DA05312, DA07746, DA11893 and DA12964.

\section{References}

Abrahams BS, Rutherford JD, Mallet PE, Beninger RJ (1998) Place conditioning with the dopamine D-1-like receptor agonist SKF 82958 but not SKF 81297 or SKF 77434. Eur J Pharmacol 343:111-118

Aquas E, Carboni E, Garau L, Di Chiara G (1990) Blockade of acquisition of drug-conditioned place aversion by $5 \mathrm{HT} 3$ antagonists. Psychopharmacology 100:459-463

Ågmo A, Marroquin E (1997) Role of gustatory and postingestive actions of sweeteners in the generation of positive affect as evaluated by place preference conditioning. Appetite 29:269289

Ågmo A, Federman I, Navarro V, Pudua M, Velazquez G (1993) Reward and reinforcement produced by drinking water: role of opioids and dopamine receptor subtypes. Pharmacol Biochem Behav 46:183-194

Antoniadis EA, Ko CH, Ralph MR, McDonald RJ (2000) Circadian rhythms, aging and memory. Behav Brain Res (in press)

Atkinson J, Enslen M (1976) Self-administration of caffeine by the rat. Arzneim Forsch 26:2059-2061

Baker DA, Khroyan TV, O'Dell LE, Fuchs RA, Neisewander JL (1996) Differential effects of intra-accumbens sulpiride on cocaine-induced locomotion and conditioned place preference. J Pharmacol Exp Ther 279:392-401

Balster RL (1990) Abuse potential of buspirone and related drugs. J Clin Psychopharmacol 10:31S-37S

Bardo MT, Neisewander JL (1986) Single-trial conditioned place preference using intravenous morphine. Pharmacol Biochem Behav 25:1101-1105

Bardo MT, Miller JS, Neisewander JL (1984) Conditioned place preference with morphine: the effect of extinction training on the reinforcing CR. Pharmacol Biochem Behav 21:545-549 
Bardo MT, Neisewander JL, Miller JS (1986) Repeated testing attenuates conditioned place preference with cocaine. Psychopharmacology 89:239-243

Bardo MT, Bowling SL, Robinet PM, Rowlett JK, Lacy M, Mattingly BA (1993) Role of $\mathrm{D}_{1}$ and $\mathrm{D}_{2}$ receptors in novelty-maintained place preference. Exp Clin Psychopharmacol 1:101109

Bardo MT, Rowlett JK, Harris MJ (1995) Conditioned place preference using opiate and stimulant drugs: a meta-analysis. Neurosci Biobehav Rev 19:39-51

Bardo MT, Valone JM, Bevins RA (1999) Locomotion and conditioned place preference produced by acute intravenous amphetamine: role of dopamine receptors and individual differences in amphetamine self-administration. Psychopharmacology 143:39-46

Barnet RC, Arnold HM, Miller RR (1991) Simultaneous conditioning demonstrated in second-order conditioning: evidence for similar associative structure in forward and simultaneous conditioning. Learn Motiv 22:253-268

Barr GA, Paredes W, Bridger WH (1985) Place conditioning with morphine and phencyclidine: dose dependent effects. Life Sci 36:363-368

Baxter BL, Gluckman MI, Scerni RA (1973) Differential self-injection behavior produced by fenfluramine versus other appetite inhibiting drugs. Fed Proc 32:754

Baxter BL, Gluckman MI, Stein L, Scerni RA (1974) Self-injection of apomorphine in the rat: positive reinforcement by a dopamine receptor stimulant. Pharmacol Biochem Behav 2:387391

Beach HD (1957) Morphine addiction in rats. Can J Psychol 11:104-112

Bedingfield JB, King DA, Holloway FA (1998) Cocaine and caffeine: conditioned place preference, locomotor activity, and additivity. Pharmacol Biochem Behav 61:291-296

Benedict JO, Ayres JJB (1972) Factors affecting conditioning in the truly random control procedure in the rat. J Comp Physiol Psychol 78:323-330

Bevins RA, Bardo MT (1998) Morphine-conditioned changes in locomotor activity: role of the conditioned stimulus. Exp Clin Psychopharmacol 6:131-138

Bevins RA, Bardo MT (1999) Conditioned increase in place preference by access to novel objects: antagonism by MK- 801 . Behav Brain Res 99:53-60

Bevins RA, McPhee JE, Rauhut AS, Ayres JJB (1997) Converging evidence for one-trial context fear conditioning with an immediate shock: importance of shock potency. J Exp Psychol [Anim Behav Proc] 23:312-324

Bolles RC (1970) Species-specific defense reactions and avoidance learning. Psychol Rev 77:32-48

Bouton ME (1993) Context, time, and memory retrieval in the interference paradigms of Pavlovian learning. Psychol Bull 114:80-99

Bouton ME, Nelson JB, Rosas JM (1999) Stimulus generalization, context change, and forgetting. Psychol Bull 125:171-186

Caine SB, Koob GF (1994) Effects of dopamine D-1 and D-2 antagonists on cocaine self-administration under different schedules of reinforcement in the rat. J Pharmacol Exp Ther 270:209-218

Caine SB, Negus SS, Mello NK, Bergman J (1999) Effects of dopamine $\mathrm{D}(1$-like) and $\mathrm{D}(2$-like) agonists in rats that self-administer cocaine. J Pharmacol Exp Ther 291:353-360
Calcagnetti DJ, Schechter MD (1992) Place conditioning reveals the rewarding aspect of social interaction in juvenile rats. Physiol Behav 51:667-672

Carr GD, White NM (1983) Conditioned place preference from intra-accumbens but not intra-caudate amphetamine injections. Life Sci 33:2551-2557

Carr GD, White NM (1986) Anatomical disassociation of amphetamine's rewarding and aversive effects: an intracranial microinjection study. Psychopharmacology 89:340-346

Carr GD, Fibiger HC, Phillips AG (1989) Conditioned place preference as a measure of drug reward. In: Liebman JM, Cooper SJ (eds) The neuropharmacological basis of reward. Clarendon Press, Oxford, pp 264-319

Cervo L, Samanin R (1995) Effects of dopaminergic and glutamatergic antagonists on the acquisition and expression of cocaine conditioning place preference. Brain Res 673:242-250

Childress AR, McLellan AT, O'Brien CP (1986) Abstinent opiate abusers exhibit conditioned craving, conditioned withdrawal and reduction in both through extinction. Br J Addict 81:644 660

Collins RJ, Weeks JR (1965) Relative potency of codeine, methadone and dihydromorphine to morphine self-maintained addict rats. Naunyn-Schmiedeberg's Arch Exp Pathol Pharmacol 249:509-514

Collins RJ, Weeks JR, Cooper MM, Good PI, Russell RR (1984) Prediction of abuse liability of drugs using IV self-administration in rats. Psychopharmacology 82:6-13

Corrigall WA, Coen KM (1989) Nicotine maintains robust self-administration in rats on a limited-access schedule. Psychopharmacology 99:473-478

Corrigall WA, Coen KM (1991) Cocaine self-administration is increased by both $\mathrm{D}_{1}$ and $\mathrm{D}_{2}$ dopamine antagonists. Pharmacol Biochem Behav 39:799-802

Cunningham CL (1995) Localization of genes influencing ethanol-induced conditioned place preference and locomotor activity in BXD recombinant inbred mice. Psychopharmacology $120: 28-41$

Cunningham CL, Dickinson SD, Grahame NJ, Okorn DM, McMullin CS (1999) Genetic differences in cocaine-induced conditioned place preference in mice depend on conditioning trial duration. Psychopharmacology 146:73-80

Dalton JCH, Vickers GJ, Roberts DCS (1986) Increased self-administration of cocaine following haloperidol: sex-dependent effects of the antiestrogen tamoxifen. Pharmacol Biochem Behav 25:497-501

Davies AM, Parker L (1993) Fenfluramine-induced place aversion in a three-choice apparatus. Pharmacol Biochem Behav 44:595-600

Deroche V, Le Moal M, Piazza PV (1999) Cocaine self-administration increases the incentive motivational properties of the drug in rats. Eur J Neurosci 11:2731-2736

de Wit H (1991) Preference procedures for testing the abuse liability of drugs in humans. Br J Addict 86:1579-1586

Di Chiara G (1999) Drug addiction as dopamine-dependent associative learning disorder. Eur J Pharmacol 375:13-30

Di Ciano P, Blaha CD, Phillips AG (1996) Changes in dopamine oxidation currents in the nucleus accumbens during unlimitedaccess self-administration of D-amphetamine by rats. Behav Pharmacol 7:714-729

Di Ciano P, Blaha CD, Phillips AG (1998) Conditioned changes in dopamine oxidation currents in the nucleus accumbens of rats 
by stimuli paired with self-administration or yoked-administration of d-amphetamine. Eur J Neurosci 10:1121-1127

Di Scala G, Sandler G (1989) Conditioned place aversion produced by FG 7142 is attenuated by haloperidol. Brain Res 483:91-97

Egger MD, Miller NE (1963) When is a reward reinforcing?: an experimental study of the information hypothesis. J Comp Physiol Psychol 56:132-137

Eikelboom R, Stewart J (1982) Conditioning of drug-induced physiological responses. Psychol Rev 89:507-528

Estes WK (1950) Toward a statistical theory of learning. Psychol Rev 57:94-107

Ettenberg A, Pettit HO, Bloom FE, Koob GF (1982) Heroin and cocaine intravenous self-administration in rats: mediation by separate neural systems. Psychopharmacology 78:204-209

Ettenberg A, Raven MA, Danluck DA, Necessary BD (1999) Evidence for opponent-process actions of intravenous cocaine. Pharmacol Biochem Behav 64:507-512

Fanselow MS (1999) Learning theory and neuropsychology: configuring their disparate elements in the hippocampus. J Exp Psychol [Anim Behav Proc] 25:275-283

File SE (1986) Aversive and appetitive properties of anxiogenic and anxiolytic agents. Behav Brain Res 21:189-194

Foltin RW, Evans SM (1997) A novel protocol for studying food of drug seeking in rhesus monkeys. Psychopharmacology 132:209-216

Gauvin DV, Dormer KN, Holloway FA (1991) Pentylenetetrazole can induce a conditioned place preference. Pharmacol Biochem Behav 40:987-990

Glick SD, Cox RD (1975) Dopaminergic and cholinergic influences on morphine self-administration in rats. Res Commun Chem Pathol Pharmacol 12:17-24

Glick SD, Merski C, Steindorf S, Wang S, Keller R W, Carlson JN (1992) Neurochemical predisposition to self-administer morphine in rats. Brain Res 578:215-220

Gluck MA, Myers CE (1997) Psychobiological models of hippocampal function in learning and memory. Annu Rev Psychol 48:481-514

Haertzen CA, Kocher TR, Miyasato K (1983) Reinforcements from the first drug experience can predict later drug habits and/or addiction: results with coffee, cigarettes, alcohol, barbiturates, minor and major tranquilizers, stimulants, marijuana, hallucinogens, heroin, opiates and cocaine. Drug Alcohol Depend 11:147-165

Hall G (1996) Learning about associatively activated stimulus representations: implications for acquired equivalence and perceptual learning. Anim Learn Behav 24:233-255

Hand TH, Stinus L, LeMoal M (1989) Differential mechanisms in the acquisition and expression of heroin-induced place preference. Psychopharmacology 98:61-67

Hemby SE, Co C, Koves TR, Smith JE, Dworkin SI (1997) Differences in extracellular dopamine concentrations in the nucleus accumbens during response-dependent and response-independent cocaine administration in the rat. Psychopharmacology $133: 7-16$

Hoffman DC (1989) The use of place conditioning in studying the neuropharmacology of drug reinforcement. Brain Res Bull 23:373-387

Hoffman DC, Dickson PR, Beninger RJ (1988) The dopamine D2 receptor agonists, quinpirole and bromocriptine produce conditioned place preferences. Prog Neuropsychopharmacol Biol Psychiatry 12:315-322
Hughes RA, Baker MR, Rettig KM (1995) Cocaine-conditioned place preference in young precocial domestic fowl. Exp Clin Psychopharmacol 3:105-111

Hughes RN (1968) Behavior of male and female rats with free choice of two environments differing in novelty. Anim Behav 16:92-96

Hull CL (1943) Principles of behavior. Appleton-Century-Crofts, New York

Ikemoto S, Panksepp J (1999) The role of nucleus accumbens dopamine in motivated behavior: unifying interpretation with special reference to reward-seeking. Brain Res Rev 31:6-41

Jones CN, Grant LD, Vospalek DM (1976) Temporal parameters of d-amphetamine as a discriminative stimulus in the rat. Psychopharmacologia 46:59-64

Kalivas PW, Sorg BA, Hooks MS (1993) The pharmacology and neural circuitry of sensitization to psychostimulants. Behav Pharmacol 4:315-334

Katz RJ, Gormezano G (1979) A rapid and inexpensive technique for assessing the reinforcing effects of opiate drugs. Pharmacol Biochem Behav 11:231-233

Kimble GA (1961) Hilgard and Marquis' conditioning and learning. Appleton-Century-Crofts, New York

Kremer EF (1974) The truly random control procedure: conditioning to the static cues. J Comp Physiol Psychol 86:700-707

Le AD, Corrigall WA, Harding JW, Juzytsch W, Li TK (2000) Involvement of nicotinic receptors in alcohol self-administration. Alcohol Clin Exp Res 24:155-163

Lepore M, Vorel SR, Lowinson J, Gardner EL (1995) Conditioned place preference induced by delta 9-tetrahydrocannabinol: comparison with cocaine, morphine, and food reward. Life Sci 56:2073-2080

Lett BT (1989) Repeated exposures intensify rather than diminish the rewarding effects of amphetamine, morphine, and cocaine. Psychopharmacology 98:357-362

Lew G, Parker LA (1998) Pentobarbital-induced place aversion learning. Anim Learn Behav 26:219-224

Liu X, Vaupel DB, Grant S, London ED (1998) Effect of cocainerelated environmental stimuli on the spontaneous electroencephalogram in polydrug abusers. Neuropsychopharmacology 19:10-17

Lubow RE, Schnur P, Rifkin B (1976) Latent inhibition and conditioned attention theory. J Exp Psychol [Anim Behav Proc] 2:163-174

Lynch (1991) Scopolamine enhances expression of an amphetamine-conditioned place preference. Neuroreport 2:715-718

Mackey WB, van der Kooy D (1985) Neuroleptics block the positive reinforcing effects of amphetamine but not of morphine as measured by place conditioning. Pharmacol Biochem Behav 22:101-105

Mackintosh NJ (1974) The psychology of animal learning. Academic Press, London

Mallet PE, Beninger RJ (1994) 7-OH-DPAT produces place conditioning in rats. Eur J Pharmacol 261:R5-6

Marquis KL, Webb MG, Moreton JE (1989) Effects of fixed ratio size and dose on phencyclidine self-administration by rats. Psychopharmacology 97:179-182

Martin-Iversen MT, Ortmann R, Fibiger HC (1985) Place preference conditioning with methylphenidate and nomifensine. Brain Res 332:59-67

Meehan SM, Schechter MD (1998) LSD produces conditioned 
place preference in male but not female fawn hooded rats. Pharmacol Biochem Behav 59:105-108

Meisel RL, Joppa MA, Rowe RK (1996) Dopamine receptor antagonists attenuate conditioned place preference following sexual behavior in female Syrian hamsters. Eur J Pharmacol 309:21-24

Morency MA, Beninger RJ (1986) Dopaminergic substrates of cocaine-induced place conditioning. Brain Res 399:33-41

Mucha RF (1987) Is the motivational effect of opiate withdrawal reflected by common somatic indices of precipitated withdrawal?: a place conditioning study in the rat. Brain Res 418:214-220

Mucha RF, Herz A (1985) Motivational properties of kappa and mu opioid receptor agonists studied with place and taste preference conditioning. Psychopharmacology 86:274-280

Mucha RF, Iversen SD (1984) Reinforcing properties of morphine and naloxone revealed by conditioned place preference: a procedural examination. Psychopharmacology 82:241-247

Mucha RF, van der Kooy D, O'Shaughnessy M, Bucenicks P (1982) Drug reinforcement studied by use of place conditioning in rat. Brain Res 243:91-105

Naruse T, Asami T (1990) Cross-dependence on ethanol and pentobarbital in rats reinforced on diazepam. Arch Int Pharmacodyn Ther 304:147-162

Neisewander JL, McDougall SA, Bowling SL, Bardo MT (1990) Conditioned taste aversion and place preference with buspirone and gepirone. Psychopharmacology 100:485-490

Neisewander JL, Baker DA, Fuchs RA, Tran-Nguyen LTL, Palmer A, Marshall JF (2000) Fos protein expression and cocaineseeking behavior in rats after exposure to a cocaine self-administration environment. J Neurosci 20:798-805

Nomikos GG, Spyraki C (1988) Cocaine-induced place conditioning: importance of route of administration and other procedural variables. Psychopharmacology 94:119-125

O’Brien CP, Childress AR, Ehrman R, Robbins SJ (1998) Conditioning factors in drug abuse: can they explain compulsion? J Psychopharmacol 12:15-22

Ortmann R (1985) The conditioned place preference paradigm in rats: effect of bupropion. Life Sci 37:2021-2027

Pain L, Oberling P, Sandner G, Di Scala G (1997) Effect of midazolam on propofol-induced positive affective state assessed by place conditioning in rats. Anesthesiology 87:935-943

Panksepp J (1998) Affective neuroscience: the foundations of human and animal emotions. Oxford University Press, New York

Papini MR, Bitterman ME (1990) The role of contingency in classical conditioning. Psychol Rev 97:396-403

Papp M (1989) Differential effects of short- and long-term antidepressant treatments on food-induced place preference conditioning in rats. Behav Pharmacol 1:69-74

Parker LA (1992) Place conditioning in a three- or four-choice apparatus: role of stimulus novelty in drug-induced place conditioning. Behav Neurosci 106:294-306

Pavlov IP (1927) Conditioned reflexes. Oxford University Press, London

Pearce JM (1994) Similarity and discrimination: a selective review of a connectionist model. Psychol Rev 101:587-607

Perks SM, Clifton PG (1997) Reinforcer revaluation and conditioned place preference. Physiol Behav 61:1-5

Phillips GD, Howes SR, Whitelaw RB, Robbins TW, Everitt BJ (1994) Isolation rearing impairs the reinforcing efficacy of in- travenous cocaine or intra-accumbens d-amphetamine: impaired response to intra-accumbens $\mathrm{D}_{1}$ and $\mathrm{D}_{2} / \mathrm{D}_{3}$ dopamine receptor antagonists. Psychopharmacology 115:419-429

Pickens R, Meisch R, McGuire LE (1967) Methamphetamine reinforcement in rats. Psychon Sci 8:371-372

Pilla M, Perachon S, Sautel F, Garrido F, Mann A, Wermuth CG, Schwartz JC, Everitt BJ, Sokoloff P (1999) Selective inhibition of cocaine-seeking behaviour by a partial dopamine $\mathrm{D}_{3}$ receptor agonist. Nature 400:371-375

Pratt JA, Stolerman IP, Garcha HS, Giardini V, Feyerabend C (1983) Discriminative stimulus properties of nicotine: further evidence for mediation at a cholinergic receptor. Psychopharmacology 81:54-60

Reid LD, Hunter GA, Beaman CM, Hubbell CL (1985) Toward understanding ethanol's capacity to be reinforcing: a conditioned place preference following injections of ethanol. Pharmacol Biochem Behav 22:483-487

Rescorla RA (1967) Pavlovian conditioning and its proper control procedures. Psychol Rev 74:71-80

Rescorla RA (1969a) Conditioned inhibition of fear resulting from negative CS-US contingencies. J Comp Physiol Psychol 67:504-509

Rescorla RA (1969b) Pavlovian conditioned inhibition. Psychol Bull 72:77-94

Rescorla RA, Wagner AR (1972) A theory of Pavlovian conditioning: variations in the effectiveness of reinforcement and nonreinforcement. In: Black AH, Prokasy WF (eds) Classical conditioning II: current research and theory. Appleton-Century-Crofts, New York, pp 64-99

Riccio DC, Richardson R, Ebner DL (1984) Memory retrieval deficits based upon altered contextual cues: a paradox. Psychol Bull 96:152-165

Robbins SJ, Ehrman RN (1992) Designing studies of drug conditioning in humans. Psychopharmacology 106:143-153

Roberts DCS, Vickers G (1984) Atypical neuroleptics increase selfadministration of cocaine: an evaluation of a behavioral screen for antipsychotic activity. Psychopharmacology 82:135-139

Roberts DCS, Loh EA, Vickers G (1989) Self-administration of cocaine on a progressive ratio schedule in rats: dose-response relationship and effect of haloperidol pretreatment. Psychopharmacology 97:535-538

Rossi NA, Reid LD (1976) Affective states associated with morphine injections. Physiol Psychol 4:269-274

Rudy JW, O’Reilly RC (1999) Contextual fear conditioning, conjunctive representations, pattern completion, and the hippocampus. Behav Neurosci 113:867-880

Savastano HI, Miller RR (1998) Time as content in Pavlovian conditioning. Behav Proc 44:147-162

Schechter MD, Calcagnetti DJ (1993) Trends in place preference conditioning with a cross-indexed bibliography: 1957-1991. Neurosci Biobehav Rev 17:21-41

Self DW, Belluzzi JD, Kossuth S, Stein L (1996) Self-administration of the $D_{1}$ receptor agonist SKF 82958 is mediated by $D_{1}$, not $\mathrm{D}_{2}$, receptors. Psychopharmacology 123:303-306

Shearman G, Hynes M, Fielding S, Lal H (1977) Clonidine self-administration in the rat: a comparison with fentanyl self-administration. Pharmacologist 19:171

Sherman JE, Pickman C, Rice A, Liebeskind JC, Holman EW (1980) Rewarding and aversive effects of morphine: temporal and pharmacological properties. Pharmacol Biochem Behav 13:501-505 
Shimosato K, Ohkuma S (2000) Simultaneous monitoring of conditioned place preference and locomotor sensitization following repeated administration of cocaine and amphetamine. Pharmacol Biochem Behav 66:285-292

Shippenberg TS, Bals-Kubik R (1995) Involvement of the mesolimbic dopamine system in mediating the aversive effects of opioid antagonists in the rat. Behav Pharmacol 6:99-106

Shippenberg TS, Elmer GI (1998) The neurobiology of opiate reinforcement. Crit Rev Neurobiol 12:267-303

Shoaib M, Stolerman IP, Kumar RC (1994) Nicotine-induced place preference following prior nicotine exposure in rats. Psychopharmacology 113:445-452

Solomon RL, Corbit JD (1974) An opponent-process theory of motivation: temporal dynamics of affect. Psychol Rev 81:119- 145

Sora I, Wichems C, Takahashi N, Li XF, Zeng Z, Revay R, Lesch KP, Murphy DL, Uhl GR (1998) Cocaine reward models: conditioned place preference can be established in dopamine- and in serotonin-transporter knockout mice. Proc Natl Acad Sci USA 95:7699-7704

Spanagel R, Weiss F (1999) The dopamine hypothesis of reward: past and current status. Trends Neurosci 22:521-527

Spragg SDS (1940) Morphine addiction in chimpanzees. Comp Psychol Monogr 15:1-132

Spyraki C, Fibiger HC, Phillips AG (1982a) Attenuation by haloperidol of place preference conditioning using food reinforcement. Psychopharmacology 77:379-382

Spyraki C, Fibiger HC, Phillips AG (1982b) Dopaminergic substrates of amphetamine-induced place preference conditioning. Brain Res 253:185-193

Spyraki C, Fibiger HC, Phillips AG (1982c) Cocaine-induced place preference conditioning: lack of effects of neuroleptics and 6hydroxydopamine lesions. Brain Res 253:195-203

Stafford D, LeSage MG, Glowa JR (1998) Progressive-ratio schedules of drug delivery in the analysis of drug self-administration: a review. Psychopharmacology 139:169-184

Stefanski R, Ladenheim B, Lee SH, Cadet JL, Goldberg SR (1999) Neuroadaptations in the dopaminergic system after active selfadministration but not after passive administration of methamphetamine. Eur J Pharmacol 371:123-135

Steinpreis RE, Rutell AL, Parrett FA (1996) Methadone produces conditioned place preference in the rat. Pharmacol Biochem Behav 54:339-341

Stewart J (1992) Conditioned stimulus control of the expression of sensitization of the behavioral activating effects of opiate and stimulant drugs. In: Gormezano I, Wasserman EA (eds) Learning and memory: the behavioral and biological substrates. LEA, Hillsdale, N.J., pp 129-151

Sutherland RJ, Rudy JW (1989) Configural association theory: the role of hippocampal formation in learning, and memory. Psychobiology 17:129-144

Suzuki T, Ise Y, Tsuda M, Maeda J, Misawa M (1996) Mecamylamine-precipitated nicotine-withdrawal aversion in rats. Eur $\mathrm{J}$ Pharmacol 314:281-284

Szostak C, Finlay JM, Fibiger HC (1987) Intravenous self-administration of the short-acting benzodiazepine midazolam in the rat. Neuropharmacology 26:1673-1676
Takahashi RN, Singer G (1979) Self-administration of $\Delta$ 9-tetrahydrocannabinol by rats. Pharmacol Biochem Behav 11:737740

Tella SR, Ladenheim B, Cadet JL (1997) Differential regulation of dopamine transporter after chronic self-administration of bupropion and nomifensine. J Pharmacol Exp Ther 281:508-513

Tierney C, Nadaud D, Koenig-Berard E, Stinus L (1988) Effects of two alpha 2 agonists, rilmenidine and clonidine, on the morphine withdrawal syndrome and their potential addictive properties in rats. Am J Cardiol 61:35D-38D

Trazon DB, Suzuki T, Misawa M, Watanabe S (1992) Methylxanthines (caffeine and theophylline) blocked methamphetamineinduced conditioned place preference in mice but enhanced that induced by cocaine. Ann NY Acad Sci 654:531-533

Tzschentke TM (1998) Measuring reward with the conditioned place preference paradigm: a comprehensive review of drug effects, recent progress and new issues. Prog Neurobiol 56:613-672

Vezina P, Stewart J (1987) Conditioned locomotion and place preference elicited by tactile cues paired exclusively with morphine in an open field. Psychopharmacology 91:375-380

Wagner AR (1981) SOP: a model of autonomic memory processing in animal behavior. In: Spear NE, Miller RR (eds) Information processing in animals: memory mechanisms. LEA, Hillsdale, N.J., pp 5-47

Wasserman EA, Miller RR (1997) What's elementary about associative learning? Annu Rev Psychol 48:573-607

Wasserman EA, Franklin SR, Hearst E (1974) Pavlovian appetitive contingencies and approach versus withdrawal to conditioned stimuli in pigeons. J Comp Physiol Psychol 86:116-

Weeks JR, Collins RJ (1987) Screening for drug reinforcement using intravenous self-administration in the rat. In: Bozarth MA (ed) Methods of assessing the reinforcing properties of abused drugs. Springer, New York, pp 35-43

White FJ, Kalivas PW (1998) Neuroadaptations involved in amphetamine and cocaine addiction. Drug Alcohol Depend 51:141-153

Winger G (1994) Dopamine antagonist effects of behavior maintained by cocaine and alfentanil in rhesus monkeys. Behav Pharmacol 5:141-152

Wise RA (1989) The brain and reward. In: Leibman JM, Cooper SJ (eds) The neuropharmacological basis of reward. Clarendon Press, Oxford, pp 377-424

Wise RA, Bozarth MA (1987) A psychomotor stimulant theory of addiction. Psychol Rev 94:469-492

Wise RA, Murray A, Bozarth MA (1990) Bromocriptine self-administration and bromocriptine-reinstatement of cocainetrained and heroin-trained lever pressing in rats. Psychopharmacology 100:355-360

Yokel RA (1987) Intravenous self-administration: response rates, the effects of pharmacological challenges, and drug preferences. In: Bozarth MA (ed) Methods of assessing the reinforcing properties of abused drugs. Springer, New York, pp 1-33

Yokel RA, Wise RA (1976) Attenuation of intravenous amphetamine reinforcement by central dopamine blockade in rats. Psychopharmacology 48:311-318 